\title{
THE ECONOMETRIC MODELING OF THE DYNAMICS OF THE ROMANIAN ECONOMIC GROWTH DURING THE PERIOD 1990-2004
}

\author{
CIPRIAN-IONEL TURTUREAN*
}

\begin{abstract}
In this paper, the author uses classical and modern econometric methods for the modeling of the economic growth rate dynamics in Romania, during the period 1990-2004. The output of this analysis is an econometric model that describes the dynamics of the economic growth process in Romania during the period 1990-2004. It represents a starting point for short and long term predictions and economic analyses.
\end{abstract}

Key words: economic growth, GDP growth rate, real GDP, time series, econometric models

\section{Introduction}

The economic growth may be defined as the increase of the production capacity of a country identified by the sustainable growth of real national income for a long period of time [Ph. Hardwick, J. Langmead, B. Khan, 2002, p. 546]. The economic growth is measured by the annual growth rate of GDP [1], GNP or national income expressed in real values obtained by correcting the current values with the deflator index.

All processes of forecast and analysis of the dynamics of a phenomenon should start from a potential model that describes the evolution of the phenomenon until the present moment and on which basis there are made projections in time for a pre-established forecast horizon.

The econometric methods used for the modeling of the annual growth rate of the real GDP can produce different models used for short term prediction, for a period less than three years.

The econometric modeling applied in this study uses Box \& Jenkins (1976) methodology based on the modeling of time using stochastic processes such as ARIMA (AutoRegressive Integrated Moving Average).

\section{The modeling of the economic growth in Romania in the period 1990-2004}

2.1 The dynamics of the real GDP and annual growth rate in Romania for the period 1990-2004

The Figures 1 and 2 present the dynamics of real GDP and real GDP growth rate for the period 1990-2004 (see Appendix: Table A.1).

The growth rate transformation has a positive influence on the series variation and it is equivalent to a logarithm transformation. It determines the stationarity in the variance of the

\footnotetext{
${ }^{*}$ Lecturer, PhD, Department of Statistics, Faculty of Faculty of Economy and Business Administration, "Alexandru Ioan Cuza" University, Iasi, e-mail: ciupan.turturean@uaic.ro
} 
real GDP original series, and increases the quality of the parameter estimations based on the observed data [Turturean, 2006, pp. 58-60]. phases:

The dynamics of the Romania's real GDP for the period 1990-2004 has four distinct

- 1990-1992 - the phase of initiation of both the economic decentralization process and the regulations of the market economy. It is characterized by a decline of the national economy reflected in the sharp decrease of real GDP and in the strong inflation.

- 1992-1996 - the phase of experimentation of the market economy. This period is characterized by the influence of the state in controlling the macroeconomic phenomena, especially in the policies against inflation and unemployment, and in finding solutions to the crisis of the previous phase. Moreover, this period is characterized by a strong development of the private sector by mass privatization and other forms of privatization of estate entreprises. It is the phase of commercial paradise.

- 1996-1999 - the phase of the development of the transition process. The tertiary sector is developing, as well as the financial sector. During this period, the Bucharest stock market expends its activity on the real estate market. During this period there are implemented long term strategies for the EU adhesion.

- 1999-2004 - the phase of the finalization of the transition process to the market economy. In this period, it is acknowledged the fact that the Romanian market economy became functional. During this phase, the effect of the long term economic strategies is obvious, as they were animated by the common objectives concerning the EU adhesion.

The evolution of the real GDP is specific to the transition period to the market economy and it comprises spells of positive and negative evolutions. These cycles are superposed on the elections periods with a time lag equal to maximum a year.

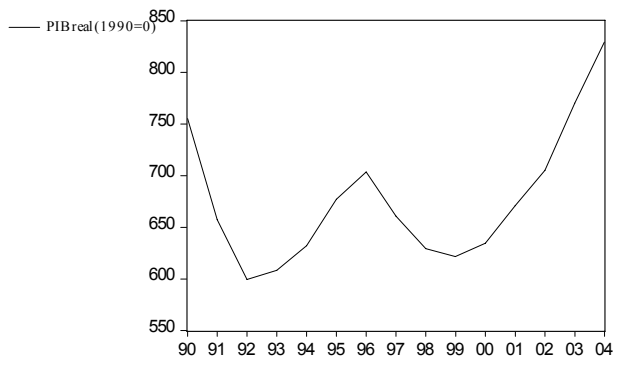

Ani

Fig. 1 Romanian real GDP dynamics during the period 1990-2004

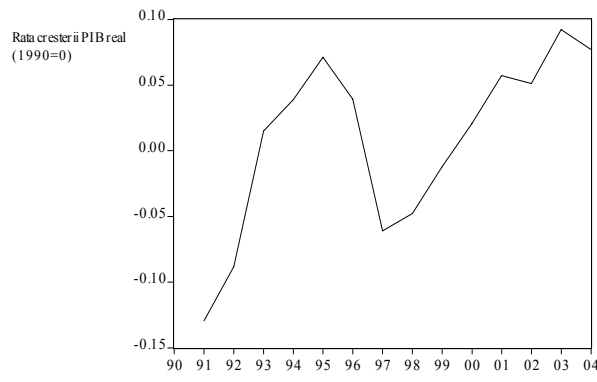

Fig. 2 Romanian real GDP growth rate dynamics during the period 1990-2004

2.2 The modeling of the dynamics of the GDP annual growth rate in Romania in the period 1990-2004

The visual analysis of the dynamics of the Romanian real GDP growth rate during the period 1990-2004 identifies an ascending trend. The nature of this trend, determinist or stochastic, will be studied by specific methods.

Firstly, we make a regression analysis of the time series for the growth rate using classical methods (see Appendix: Table A.2), and we identify a determinist trend (DT) estimated by the following relation (1).

$\mathrm{x}_{\mathrm{t}}=-0,32+0,129 \mathrm{t}-0,016 \mathrm{t}^{2}+0,001 \mathrm{t}^{3}+\delta_{\mathrm{t}}$

where: $x_{t}-$ the growth rate specific to the time period $[t-1 ; t)$, calculated on the basis of the real GDP (see column 6 Appendix: Table A.1); 
$\mathrm{t}-$ the ranks of the years in ascending order, $\mathrm{t}=\overline{1,14}$;

$\delta_{t}-$ the modeling error calculated as the difference between empirical values of the growth rate and the theoretical values calculated on the basis of the estimated model: $\delta_{\mathrm{t}}=\mathrm{x}_{\mathrm{t}}-\left(-0,32+0,129 \mathrm{t}-0,016 \mathrm{t}^{2}+0,001 \mathrm{t}^{3}\right)$

The diagram of the series adjusted by the cubic model presented by the relation (1) is shown in Figure 3.

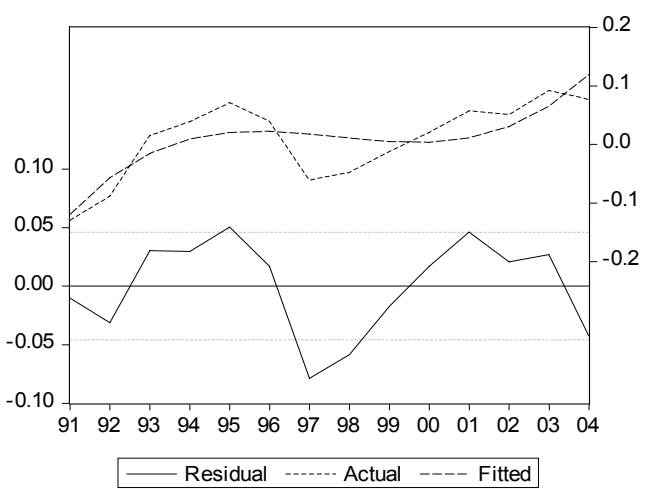

Fig. 3 The dynamics of the real GDP growth rate, of the real GDP growth rate adjusted by a third degree polynomial model and of the modeling residue resulted by the adjustment of the Romanian GDP growth rate in the period 1990-2004

In the modeling process of the real GDP growth rate $\left(\mathrm{x}_{\mathrm{t}}\right)$, using the cubic model estimated by the relation (1), we obtain a variable named error model $\left(\delta_{t}\right)$. The modeling of this variable will be done in the second part of the modeling process using modern methods of regression analysis for time series, namely stochastic methods.

Applying the Augmented Dickey Fuller test [Dickey, D.A., Fuller W.A., 1979, pp. 427-431] (see Table A.3) we can assume, with a risk of 5\%, that the model error $\left(\delta_{t}\right)$ does not contain the component stochastic trend and, therefore, there is no need of differencing the series terms. This is equivalent to the fact that the series $\delta_{\mathrm{t}}$ is an integrated series of order $\mathrm{d}=0$, and we write it $\mathrm{I}(0)$. The component model error $\left(\delta_{t}\right)$ will be modeled by an ARIMA $(\mathrm{p}, 0, \mathrm{q})$ model or by a simple ARMA $(\mathrm{p}, \mathrm{q})$ model.

In order to identify the structure of the ARMA model, we will study the autocorrelation function (ACF) plot and the partial autocorrelation function (PACF) plot (see Appendix: Fig. A.1 and A.2) for a number of maximum 12 lags.

The plots presented in figures A.1 and A.2 suggest that we should use, for the modeling of the $\delta_{t}$, a MA (4) model. After estimating the parameters of this model (Appendix: Table A.4) we notice that the estimated model does not ensure that the stochastic process is invertible. The main effect of a non-invertible model is the increase of the weight of the observations as they move away from the studied moment, contrary to the reality [Turturean, 2006, p. 127]. As a consequence, we drop the MA(4) model in favor of a MA(3) model (Appendix: Table A.5) presented through the relation (2).

$\delta_{\mathrm{t}}=\varepsilon_{\mathrm{t}}-0,916 \varepsilon_{\mathrm{t}-3}$

where:

$\delta \mathrm{t}$ - the model error calculated as difference between the empirical values of the growth rate and the theoretical values obtained by the estimated model: $\delta_{\mathrm{t}}=\mathrm{x}_{\mathrm{t}}-\left(-0,32+0,129 \mathrm{t}-0,016 \mathrm{t}^{2}+\right.$ $\left.0,001 \mathrm{t}^{3}\right)$

$\varepsilon_{t}, \varepsilon_{t-3}$ - the error at the $t$ moment and the previous error for lag 3 resulted from modeling $\delta_{t}$ with a MA(3) model presented in the relation (2). 


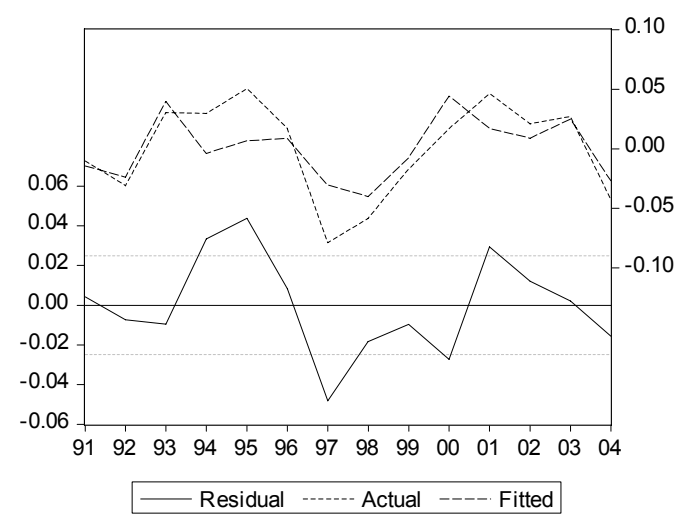

Fig. 4 The dynamics of the model error series $\left(\delta_{t}\right)$, the plot of the adjusted series using a MA(3) model and the plot of the model residue resulted from modeling $\delta_{t}$ with a MA(3) model

The model error $\left(\varepsilon_{t}\right)$ resulted from the process of modeling $\delta_{t}$ with a MA(3) model presented in relation (2) should fulfill three assumptions [Jaba, Jemna, 2007, pp. 83-95]:

1. The assumption of normality is verified by the results of the Jarque-Bera [Bera A K., Jarque C. M., 1980, pp. 255-259] test applied to the model residue $\left(\varepsilon_{t}\right)$ (see Appendix: Figure A.3);

2. The assumption of homoscedasticity is verified by the results of the non parametric correlation test between variables: $\delta_{t}$ and $\left|\varepsilon_{t}\right|$ (see Appendix: Table A.6);

3. The assumption of independence of the model residue $\left(\varepsilon_{t}\right)$ is verified by the appropriate correlograms (see Appendix: Figure A.4 and Figure A.5).

The three assumptions being verified, we can suppose that the model residue $\left(\varepsilon_{t}\right)$ is a white noise process that follows a normal distribution [Turturean, 2006, p.35].

\section{Conclusions}

Through the modeling process of the real GDP growth rate in Romania during the period 1990-2004, we obtained a mixed univariate econometric model described by two regression equations:

$\mathrm{x}_{\mathrm{t}}=-0,32+0,129 \mathrm{t}-0,016 \mathrm{t}^{2}+0,001 \mathrm{t}^{3}+\delta_{\mathrm{t}}$

$\delta_{\mathrm{t}}=\varepsilon_{\mathrm{t}}-0,916 \varepsilon_{\mathrm{t}-3}$

The first equation is specific to a determinist trend modeled by a third degree polynomial curve. The second equation is specific to a stochastic model, namely a third order moving average (MA (3)). The second model is obtained for the variable model residue $\left(\delta_{t}\right)$ resulted by adjusting the real GDP growth rate $\left(\mathrm{x}_{\mathrm{t}}\right)$ by a cubic model estimated in the relation (1).

This model may be used for short term predictions of the Romanian economic growth. From 1996, the real GDP growing rate followed a constant increase excepting 2 periods of recession between 2000-2001 and 2003-2004 (see Figure A.2).

In the period following 2004, though a Real GDP Growth is expected, it must be taken into account that this growth cannot be infinite, therefore it's recommended to wisely use the forecasts and to only make them for very short period of time.

While the representative sample, on which the estimates are done, grows we will take into consideration other aspects: 
1. dropping the real GDP growing rate values between 1991-1997, because there are too big variations of it on account of economic instability which characterized Romania in this period.

2. testing the trend break points for the studied series

3. adjusting tendencies with different models for the different periods.

\section{References}

Bera, A. K., Jarque C. M., Efficient tests for normality, homoscedasticity and serial independence of regression residuals, Economics Letters 6 (3): 255-259, Elsevier Editors Home, 1980

Box G. E. P., G. M. Jenkins, The time series analysis:Forecasting and control, 1976, , Ed. Holden Day, San Francisco, 1976

Dickey, D.A., Fuller W.A., Distribution of the Estimators for Autoregressive Time Series with a Unit Root, Journal of the American Statistical Association, 74, 427-431, 1979.

Hardwick Ph., Langmead J., Khan B., Introducere în economia politică modernă, Ed.

Polirom, IAŞI, 2002

Jaba E., Jemna D, Econometrie, Ed. Sedcom Libirs, Iaşi, 2007

Popescu Th., Serii de timp-Aplicații în analiza sistemelor, Ed. Tehnică, Bucureşti,2000

Pydyck R. S., Rubinffeld, Econometric Models and Econometric Forecasts, Ed. Mc. GrawHill Inc., New York, , 1991

Turturean C. I., Metode statistice de analiză a seriilor de timp, Ed. Sedcom Libris, Iaşi, 2006

***, NBR Annual report, 2004

\section{Notes}

1. Calculated as return rate of real GDP. 


\section{APPENDIX}

Table no. A.1: GDP values and deflator index for the period 1990-2004

\begin{tabular}{|c|c|c|c|c|c|c|}
\hline $\begin{array}{c}\text { Year's } \\
\text { Rank (t) }\end{array}$ & Year & $\begin{array}{l}\text { GDP }^{\mathrm{t}} \text { curr. pr. } \\
\text { (bil. ROL) }\end{array}$ & $D^{t / t-1}$ & $\begin{array}{c}D^{t / 0} \\
1989=0\end{array}$ & $\begin{array}{c}\text { GDP }^{\mathrm{t} / 0} \text { comp. pr. } \\
1989=0,(\text { bil. ROL) }\end{array}$ & rGDP $^{t / t-1}$ \\
\hline 1 & 1990 & 857,9 & 1,136 & 1,136 & 755,1937 & $\overline{-----}$ \\
\hline 2 & 1991 & 2203,9 & 2,951 & 3,352 & 657,4222 & $-0,129$ \\
\hline 3 & 1992 & 6029,2 & 3,000 & 10,057 & 599,5024 & $-0,088$ \\
\hline 4 & 1993 & 20035,7 & 3,274 & 32,927 & 608,4950 & 0,015 \\
\hline 5 & 1994 & 49773,2 & 2,391 & 78,728 & 632,2204 & 0,039 \\
\hline 6 & 1995 & 72135,5 & 1,353 & 106,518 & 677,2113 & 0,071 \\
\hline 7 & 1996 & 108919,6 & 1,453 & 154,771 & 703,7454 & 0,039 \\
\hline 8 & 1997 & 252925,7 & 2,473 & 382,749 & 660,8127 & $-0,061$ \\
\hline 9 & 1998 & 373798,2 & 1,552 & 594,027 & 629,2611 & $-0,048$ \\
\hline 10 & 1999 & 545730,2 & 1,478 & 877,972 & 621,5803 & $-0,012$ \\
\hline 11 & 2000 & 803773,1 & 1,443 & 1266,914 & 634,4339 & 0,021 \\
\hline 12 & 2001 & 1167687,0 & 1,374 & 1740,740 & 670,7994 & 0,057 \\
\hline 13 & 2002 & 1514750,9 & 1,234 & 2148,073 & 705,1675 & 0,051 \\
\hline 14 & 2003 & 1975648,1 & 1,194 & 2564,799 & 770,2936 & 0,092 \\
\hline 15 & 2004 & 2463716,5 & 1,158 & 2970,037 & 829,5239 & 0,077 \\
\hline
\end{tabular}

Source: [***, NBR Annual report, 2004]

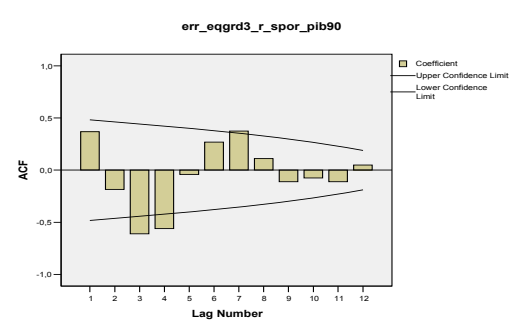

Fig. A.1: ACF correlogram for the variable $\delta_{t}$ calculated for maximum 12 lags

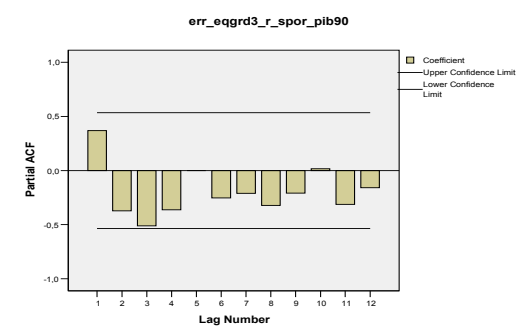

Fig. A.2: Partial ACF correlogram for the variable $\delta_{t}$ calculated for maximum 12 lags

Table no. A.2: Cubic Regression Model Summary

\begin{tabular}{|c|c|c|c|c|c|c|c|}
\hline $\mathbf{R}$ & $\mathbf{R}^{2}$ & Adj. $R^{2}$ & $\mathbf{F}$ & X Coeff. & $X^{2}$ Coeff. & $\mathrm{X}^{3}$ Coeff. & Const. \\
\hline 0,650 & 0,422 & 0,249 & 5,971 & 0,129 & $-0,016$ & 0,001 & $-0,32$ \\
\hline \multicolumn{3}{|c|}{ Sig. } & 0,013 & 0,032 & 0,033 & 0,013 & 0,023 \\
\hline
\end{tabular}

The independent variable is R_SOM.

Table no. A.3: Stochastic Trend test applied to modeling error $\left(\delta_{\mathrm{t}}\right)$ without differencing

\begin{tabular}{|l|l|l|l|}
\hline ADF Test Statistic & $-2,145569$ & $5 \%$ Critical Value & $-1,9699$ \\
\hline
\end{tabular}

*MacKinnon critical values for rejection of hypothesis of a unit root 
Table no. A.4: Parameters estimates for the MA(0,4)model and the statistic indicators of the "model performance"

\begin{tabular}{|c|c|c|c|c|c|c|c|c|c|c|}
\hline & Coef. & $\begin{array}{c}\text { Std. } \\
\text { Error }\end{array}$ & $\begin{array}{c}\mathbf{t} \\
\text { Stat. }\end{array}$ & Prob. & $\mathbf{R}^{2}$ & $\underset{\mathbf{R}^{2}}{\text { Adj. }}$ & $\begin{array}{l}\text { S.E. of } \\
\text { Regres. }\end{array}$ & $\begin{array}{c}\text { Sum } \\
\text { Squar. Res. }\end{array}$ & $\begin{array}{c}\text { Akaike } \\
\text { info crit. }\end{array}$ & $\begin{array}{c}\text { Schwarz } \\
\text { crit. }\end{array}$ \\
\hline$M A(3)$ & $-0,890$ & 0,161 & $-5,518$ & 0,000 & 0,750 & 0,729 & 0,021 & 0,005 & $-4,763$ & $-4,672$ \\
\hline$M A(4)$ & $-1,546$ & 0,171 & $-9,048$ & 0,000 & & & & & & \\
\hline \multicolumn{3}{|c|}{ Inverted MA Roots } & & 1,28 & & $-0,18+1,13 \mathrm{i}$ & & $-0,18-1,13 \mathrm{i}$ & & $-0,92$ \\
\hline \multicolumn{11}{|c|}{ Estimated MA process is noninvertible } \\
\hline
\end{tabular}

Table no. A.5: Parameters estimates for the MA(0,3) model and the statistic indicators of the "model performance"

\begin{tabular}{|c|c|c|c|c|c|c|c|c|c|c|}
\hline & Coef. & $\begin{array}{c}\text { Std. } \\
\text { Error }\end{array}$ & $\begin{array}{c}\mathrm{t} \\
\text { Stat. }\end{array}$ & Prob. & $\mathbf{R}^{2}$ & $\begin{array}{c}\text { Adj. } \\
\mathbf{R}^{2}\end{array}$ & $\begin{array}{l}\text { S.E. of } \\
\text { Regres. }\end{array}$ & $\begin{array}{c}\text { Sum } \\
\text { Squar. Res. }\end{array}$ & $\begin{array}{c}\text { Akaike } \\
\text { info crit. }\end{array}$ & $\begin{array}{c}\text { Schwarz } \\
\text { crit. }\end{array}$ \\
\hline$M A(3)$ & $-0,916$ & 0,073 & $-12,621$ & 0,000 & 0,619 & 0,619 & 0,025 & 0,008 & $-4,485$ & $-4,439$ \\
\hline \multicolumn{3}{|c|}{ Inverted MA Roots } & & 0,97 & & \multicolumn{2}{|c|}{$-0,49+0,84 \mathrm{i}$} & \multicolumn{3}{|c|}{$-0,49-0,84 i$} \\
\hline
\end{tabular}

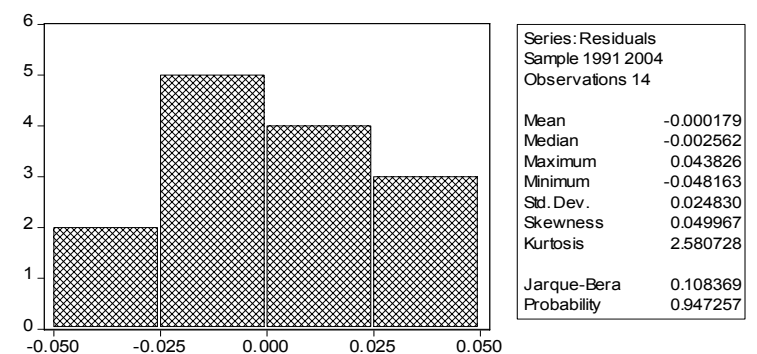

Fig. A.3: Distribution of residual modeling variable $\left(\varepsilon_{t}\right)$ and normality hypothesis test

Table no. A.6: „Non parametric correlation test between variables: $\delta_{t}$ and $\left|\varepsilon_{t}\right|$ ”

\begin{tabular}{|l|l|l|r|}
\hline & & & \multicolumn{1}{|c|}{$\boldsymbol{\delta}_{\mathbf{t}}$} \\
\hline \multirow{2}{*}{ Spearman's rho } & \multirow{2}{*}{$\boldsymbol{\varepsilon}_{\mathbf{t}}$} & Corel. Coeff. & $-0,064$ \\
\cline { 3 - 4 } & & Sig. (2-tailed) & 0,829 \\
\hline
\end{tabular}

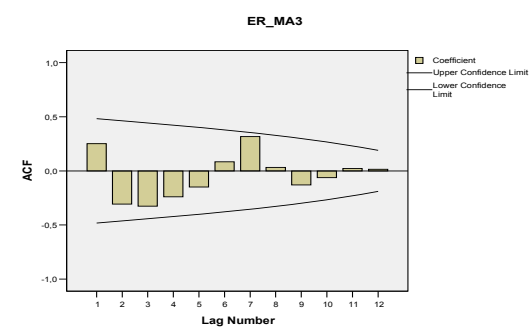

Fig. A.4: ACF correlogram for the variable $\varepsilon_{t}$ calculated for maximum 12 lags

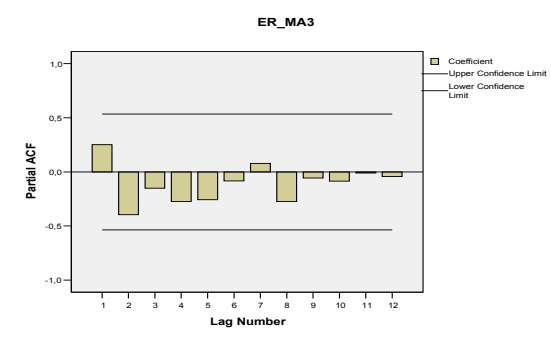

Fig. A.5: Partial ACF correlogram for the variable $\varepsilon_{t}$ calculated for maximum 12 lags 